\title{
New Palladacycle-Derived Acylhydrazones as Pre-catalysts in Mirozoki-Heck Coupling and Oxyarylations
}

\author{
RAQUEL A.C. LEÃO ${ }^{1,2}$, VAGNER D. PINHO ${ }^{1}$, ARTUR S. COELHO ${ }^{1}$, \\ ARTHUR E. KÜMMERLE ${ }^{3}$ and PAULO R.R. COSTA ${ }^{1}$

\begin{abstract}
${ }^{1}$ Laboratório de Química Bioorgânica, Instituto de Pesquisa de Produtos Naturais, Centro de Ciências da Saúde, Universidade Federal do Rio de Janeiro, B1 H, Ilha da Cidade Universitária, 21941-590 Rio de Janeiro, RJ, Brazil

${ }^{2}$ Faculdade de Farmácia, Universidade Federal do Rio de Janeiro, Av. Carlos Chagas

Filho, 373, Cidade Universitária, 21941-170 Rio de Janeiro, RJ, Brazil

${ }^{3}$ Departamento de Química, Instituto de Ciências Exatas, Universidade Federal Rural do Rio de

Janeiro, Rodovia BR 465, Km 07, Zona Rural, 23890-000 Seropédica, RJ, Brazil
\end{abstract}

Manuscript received on October 25, 2017; accepted for publication on January 12, 2018

\begin{abstract}
New acylhydrazone-based palladacycles are prepared and evaluated as pre-catalysts in Mirozoki-Heck and oxyarylation reactions.
\end{abstract}

Key words: acylhydrazone, palladacycle, Mirozoki-Heck reaction, oxyarylation.

\section{INTRODUCTION}

Palladacycles were discovered in the mid1960 s as intermediates in palladium- mediated transformations and have been employed as active intermediates in cascade transformations leading to complex molecular architectures (Beletskaya and Cheprakov 2004, Dupont et al. 2005).

Since the preparation of the cyclopalladate tri$o$-tolyl-phosphine complex reported by Herman (Hermann et al. 1995, 1999) and its use as a precatalyst for palladium-catalyzed Mirozoki-Heck and other cross-coupling reactions, the use of palladacycles has experienced tremendous growth

Correspondence to: Paulo R.R. Costa

E-mail: prrcosta2011@gmail.com

* Contribution to the centenary of the Brazilian Academy of Sciences.
(Beletskaya and Cheprakov 2004, Dupont et al. 2005).

Their high thermal stability in the solid state, easy preparation and ready modulation of both steric and electronic properties make them affordable tools in organic synthesis. In fact, a large number of new palladacycles have been prepared and used as pre-catalysts (Alonso et al. 2000, Nájera 2016).

Despite some suggestion of a mechanism involving $\mathrm{Pd}(\mathrm{II})$ and $\mathrm{Pd}(\mathrm{IV})$ species (Shaw et al. 1998a, Shaw 1998), they are considered as a source of in situ formed $\mathrm{Pd}(0)$ nanoparticles, which have been successfully used in several coupling reactions in low catalytic loading. In addition, palladacycles can be prepared in water and do not require the presence of ligands, making their use very attractive (Beletskaya and Cheprakov 2004, Dupont et al. 2005). 
Although some hydrazone-based palladacycles are known in the literature and promote SuzykiMiyaura and Mirozoki-Heck coupling reactions (Cardenas and Echavarren 1995, Nagy et al. 2005), herein we describe the first synthesis and application of acyl-hydrazone-based paladacycles as pre-catalysts in Mirozoki-Heck and oxyarylation reactions.

\section{DISCUSSION AND RESULTS}

Acylhydrazones (1a-c) are easily prepared by the reaction of acylhydrazines with aromatic aldehydes and have been extensively used as a platform to construct interesting biologically active compounds (Fraga and Barreiro 2006).

The new palladacycles 2a-c were prepared by electrophilic $\mathrm{C}-\mathrm{H}$ activation of acylhydrazones 1a-c with $\mathrm{Li}_{2} \mathrm{PdCl}_{4}$ in methanol in the presence of $\mathrm{NaOAc}$ as the base at room temperature (Figure 1) (Alonso et al. 2002). Compounds 2a-c precipitated from the reaction medium and were obtained as yellowish stable solids after filtration.

Once ${ }^{1} \mathrm{H}$ NMR spectra are complex to analyze the structures of $\mathbf{2 a - c}$ were determined by indirect way. Palladacycles 2a and $\mathbf{2 c}$ were reduced with $\mathrm{NaCNBD}_{3}$ in THF/MeOH (Figure 2) (Alonso et al. 2002) leading to the respective deuterated acylhydrazones $\mathbf{3} \mathbf{a}$ and $\mathbf{3 c}$, which were characterized by GC/MS and ${ }^{1} \mathrm{H}$ NMR. Also, the palladacycle $\mathbf{2 b}$ was reduced under the same conditions, yielding the acylhydrazone $\mathbf{3 b}(\mathrm{GC} / \mathrm{MS})$.

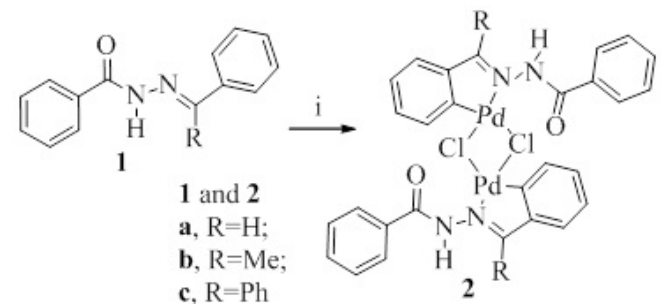

i, $\mathrm{Li}_{2} \mathrm{PdCl}_{4}$, NaOAc, $\mathrm{MeOH}$, r.t., 3 days. 2a, 63\%; 2b, 57\%, 2c, $67 \%$

Figure 1 - Preparation of the palladacycles 2a-c.

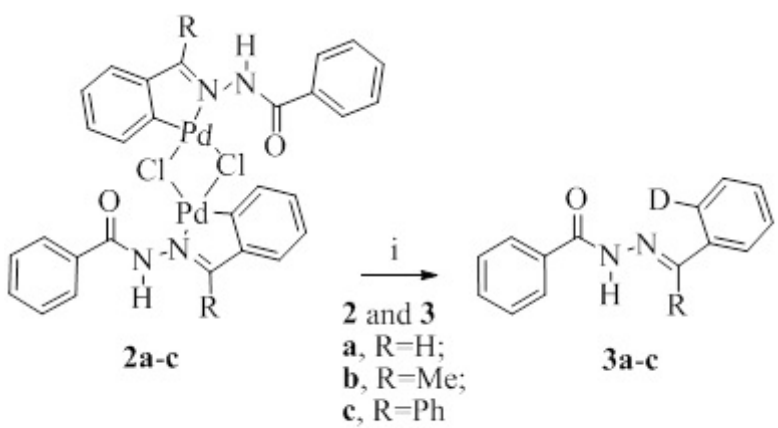

i. $\mathrm{NaBD}_{3} \mathrm{CN}, \mathrm{THF} / \mathrm{MeOH}, 0^{\circ} \mathrm{C}$-r.t., $1 \mathrm{~h}$

Figure 2 - Reduction of the palladacycles $\mathbf{2 a - c .}$

A fragment of the oxonium ion at $\mathrm{m} / \mathrm{z}=105$ was the base peak in all three cases (Figure 3). Since this fragment does not present deuterium in its structure, the $\mathrm{Pd}-\mathrm{C}$ bond in palladacycles $\mathbf{2 a - c}$ must be located at the $\mathrm{B}$ ring. Deuterated acylhydrazones $\mathbf{3 a}$ and $\mathbf{3 c}$ led to a deuterated fragment at $\mathrm{m} / \mathrm{z}=$ 224 , while for $\mathbf{3 b}$ a fragment was observed at $\mathrm{m} / \mathrm{z}$ $=147$, by releasing a deuterated phenyl group. These analyses clearly indicate that the deuterium is located in the B-ring, in accordance with the proposed structures of $\mathbf{2 a - c .}$

To demonstrate the efficiency of these new acylhydrazone-based palladacycles, they were evaluated in the Mirozoki-Heck reaction between iodobenzene (4) and methyl acrylate (5). The yield of methyl cinnamate (6) and the major reaction conditions studied are shown in Figure 4 and Table I. Triethylamine was used as the base and after 10 $\mathrm{h}$ at $110{ }^{\circ} \mathrm{C}$ in the presence of $0.1 \mathrm{~mol} \% \mathrm{Pd}$ source, 6 was obtained in excellent yield, regardless of the pre-catalyst used (entries 1-3, Table I). Similar yields were obtained in the presence of $0.001 \mathrm{~mol} \%$ of 2a-c, but using a more prolonged reaction time (entries 3-6, Table I). Similar results were obtained when DIPEA was used as the base (entries 7 and 8 , Table I) but yields decreased in the presence of $\mathrm{Na}_{2} \mathrm{CO}_{3}$ (entries 9-11, Table I). The yields were still good when MeCN or NMP were employed as solvents (entries 12-16, Table I). However, no reaction was observed when the reaction was 


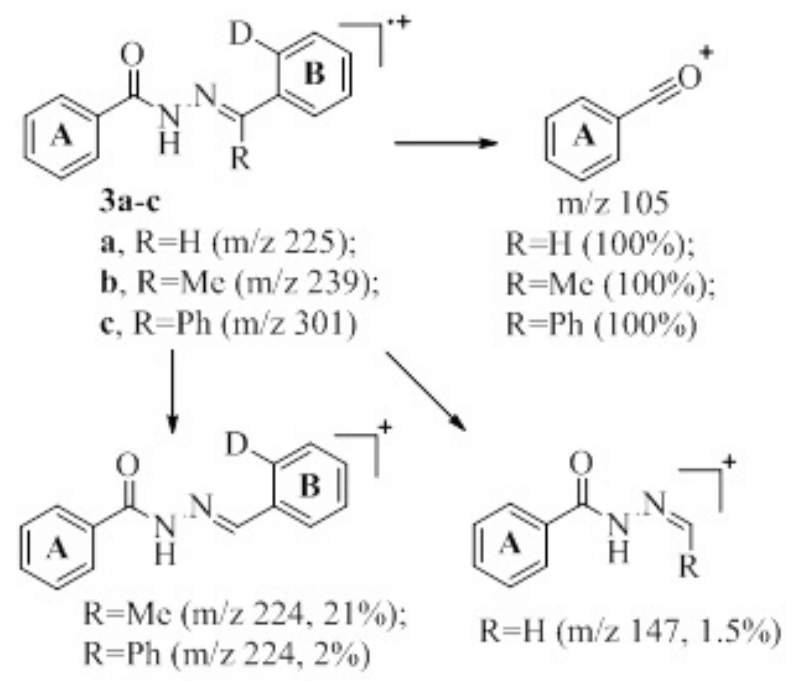

Figure 3 - Proposed mechanism for the fragmentation of 3a-c.

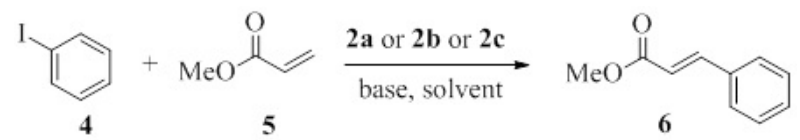

Figure $\mathbf{4}$ - Mirozoki-Heck reaction of $\mathbf{4}$ and $\mathbf{5}$ in palladacycles 2a-c as pre-catalysts.

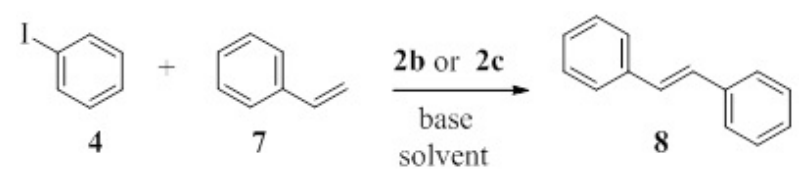

Figure 5 - Mirozoki-Heck reaction of 4 and 7 in palladacycles 2a,b. conducted in the mixture DIPEA-water (data not shown).

Next, we studied the Mirozoki-Heck reaction between 4 and styrene (7), shown in Figure 5 and Table II. Stilbene (8) was obtained in reasonable yield when $0.1 \mathrm{~mol} \% \mathbf{2 b}$ or $\mathbf{2 c}$ were used as precatalyst (entries 1 and 2, Table II) but the yield decreased when $0.001 \mathrm{~mol} \%$ of pre-catalyst was employed (entries 3 and 4, Table II).

Finally, we turned our attention to a more challenging transformation, the oxyarylation reaction. The first catalytic version of the oxyarylation reaction was reported (Larock 1998) under conditions that favored the neutral pathway. Kiss et al. (2003) reported the use of silver carbonate as base, conditions where the cationic mechanism is favored.

The scope of this reaction in the presence of $\mathrm{Ag}_{2} \mathrm{CO}_{3}$ was studied by our group and a cationic palladacycle formed in the migratory insertion step could be intercepted by ESI-MS and characterized by ESI-MS/MS (Buarque et al. 2010). As the carbopalladation step occurs with the attachment of the aryl group and the palladium atom in the same face of the olefin, the cis-stereoselectivity observed in oxyarylation reaction can be understood by

TABLE I

Yields and main conditions for reactions shown in Figure 4.

\begin{tabular}{|c|c|c|c|c|c|c|}
\hline entry & Solvent & Base & Pd(mol\%) & $\mathrm{T}\left({ }^{\circ} \mathrm{C}\right)$ & Time (h) & Yield (\%) \\
\hline 1 & DMF & TEA & $0.1(\mathbf{2 a})$ & 110 & 10 & 96 \\
\hline 2 & DMF & TEA & $0.1(\mathbf{2 b})$ & 110 & 10 & 98 \\
\hline 3 & DMF & TEA & $0.1(2 \mathrm{c})$ & 110 & 10 & 98 \\
\hline 4 & DMF & TEA & $0.001(\mathbf{2 a})$ & 110 & 24 & 80 \\
\hline 5 & DMF & TEA & $0.001(2 \mathbf{b})$ & 110 & 24 & 95 \\
\hline 6 & DMF & TEA & $0.001(1 \mathrm{c})$ & 110 & 24 & 95 \\
\hline 7 & DMF & DIPEA & $0.001(\mathbf{2 a})$ & 110 & 24 & 85 \\
\hline 8 & DMF & DIPEA & $0.001(2 b)$ & 110 & 24 & 80 \\
\hline 9 & DMF & $\mathrm{Na}_{2} \mathrm{CO}_{3}$ & $0.001(\mathbf{2 a})$ & 110 & 24 & 65 \\
\hline 10 & DMF & $\mathrm{Na}_{2} \mathrm{CO}_{3}$ & $0.001(\mathbf{2 b})$ & 110 & 24 & 72 \\
\hline 11 & DMF & $\mathrm{Na}_{2} \mathrm{CO}_{3}$ & $0.001(2 c)$ & 110 & 24 & 70 \\
\hline 12 & $\mathrm{MeCN}$ & TEA & $0.001(\mathbf{2 a})$ & 80 & 24 & 90 \\
\hline 13 & $\mathrm{MeCN}$ & TEA & $0.001(2 \mathbf{b})$ & 80 & 24 & 92 \\
\hline 14 & $\mathrm{MeCN}$ & TEA & $0.001(2 \mathrm{c})$ & 80 & 24 & 92 \\
\hline 15 & NMP & TEA & $0.001(\mathbf{2 b})$ & 110 & 24 & 80 \\
\hline 16 & NMP & TEA & $0.001(1 \mathrm{c})$ & 110 & 24 & 75 \\
\hline
\end{tabular}


TABLE II

Yields and main conditions for the reaction shown in Figure 5.

\begin{tabular}{ccccccc}
\hline entry & Solvent & Base & $\begin{array}{c}\text { Pd } \\
(\mathbf{m o l} \%)\end{array}$ & $\begin{array}{c}\text { T } \\
\left({ }^{\mathbf{0}} \mathbf{C}\right)\end{array}$ & $\begin{array}{c}\text { Time } \\
(\mathbf{h})\end{array}$ & $\begin{array}{c}\text { Yield } \\
(\mathbf{\%})\end{array}$ \\
\hline 1 & DMF & TEA & $0.1(\mathbf{2 b})$ & 110 & 24 & 67 \\
2 & DMF & TEA & $0.1(\mathbf{2 c})$ & 110 & 24 & 60 \\
3 & DMF & TEA & $0.001(\mathbf{2 b})$ & 110 & 24 & 50 \\
4 & DMF & TEA & $0.001(\mathbf{2 c})$ & 110 & 24 & 45 \\
\hline
\end{tabular}

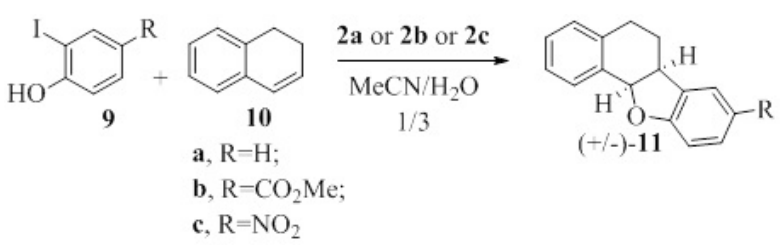

Figure 6 - Oxyarylation reaction of $\mathbf{1 0}$ with 9 in the presence of palladacycles $\mathbf{2 a - c}$.

the retention of configuration in the course of the formation of $\mathrm{O}-\mathrm{C}$ bond in the reductive elimination step (Buarque et al. 2010).

The Najera's palladacycle also catalyzed these reactions, but the mechanism was not studied under these conditions (Leão et al. 2011). The use of PEG-400 as solvent and additive was also reported (de Moraes et al. 2015).

The oxyarylation reaction of dihydronaphthalene 10 with ortho-iodophenols 9a-c was used in order to evaluate the efficiency of the palladacycles 2a-c. (Figure 6 and Table III). Interestingly, these reactions did not proceed when performed in DMF. However, compounds 11a-c were obtained in reasonable yields using the mixture $\mathrm{MeCN}-\mathrm{H}_{2} \mathrm{O}$ $\left(\mathrm{MeCN}-\mathrm{H}_{2} \mathrm{O}=1 / 3\right)$, irrespective of the pre-catalyst used (entries 1-5, Table III). Yields for 11a are higher than that obtained with Najera's palladacycle (35\% under thermal conditions, data not shown) (Leão et al. 2011). In contrast, for reactions using silver carbonate as base (de Moraes et al. 2015) the yields did not depend on the pattern of substitution in 9.

\section{CONCLUSIONS}

In summary, we describe the synthesis of new acylhydrazone-based palladacycles and their
TABLE III

Yields and main conditions for the reaction shown in Figure 6.

\begin{tabular}{ccccccc}
\hline entry & ArI & $\begin{array}{c}\text { Pd } \\
(\mathbf{1 m o l} \%)\end{array}$ & Product & $\begin{array}{c}\mathbf{T} \\
(\mathbf{}\end{array}$ & $\begin{array}{c}\text { Time } \\
\text { (h) }\end{array}$ & $\begin{array}{c}\text { Yield } \\
\mathbf{( \% )}\end{array}$ \\
\hline 1 & $\mathbf{9 a}$ & $\mathbf{2 a}$ & $\mathbf{1 1 a}$ & 120 & 12 & 50 \\
2 & $9 \mathrm{a}$ & $\mathbf{2 b}$ & $11 \mathrm{a}$ & 120 & 12 & 55 \\
3 & $\mathbf{9 a}$ & $\mathbf{2 c}$ & $\mathbf{1 1 a}$ & 120 & 12 & 56 \\
4 & $\mathbf{9 b}$ & $\mathbf{2 c}$ & $\mathbf{1 0 b}$ & 120 & 12 & 52 \\
5 & $\mathbf{9 c}$ & $\mathbf{2 c}$ & $\mathbf{1 0 c}$ & 120 & 12 & 53 \\
\hline
\end{tabular}

application as efficient pre-catalysts in MirozokiHeck and oxyarylation reactions in reasonable to good yield using low catalytic load.

\section{EXPERIMENTAL SECTION}

\section{GENERAL}

All the reagents and solvents were purchased from Aldrich Chem. Co. and used without purification. Melting points were determined with a ThomasHoover apparatus. Column chromatography was performed on flash silica 0.035-0.070 mm (Acros). IR spectra were obtained in an IR Prestige-21 Shimadzu. NMR spectra were recorded on a Varian 400 (400 MHz) spectrometer. Low-resolution mass spectra were obtained from a GCMS-QP 5000 Plus Shimadzu.

\section{SYNTHESIS OF ACYLHYDRAZONES 1a-c}

To a solution of benzohydrazide $(0.3 \mathrm{~g} ; 2.20 \mathrm{mmol})$ in absolute ethanol $(5 \mathrm{~mL})$ containing three drops of $37 \%$ hydrochloric acid, was added $2.31 \mathrm{mmol}$ of the appropriated aromatic carbonyl. The mixture was stirred at $70{ }^{\circ} \mathrm{C}$ for 8 hours when an extensive precipitation occurs. The mixture was poured into cold water, neutralized with $10 \%$ aqueous sodium bicarbonate solution and the precipitate was filtered off and washed several times with petroleum ether.

Acylhydrazone 1a: 55\%; Mp 205-206 ${ }^{\circ} \mathrm{C} .{ }^{1} \mathrm{H}$ RMN (400 MHz, DMSO-d $)$, d(ppm): d11.85 (s, $1 \mathrm{H}), 8.48(\mathrm{~s}, 1 \mathrm{H}), 7.93(\mathrm{~d}, J=7.35 \mathrm{~Hz}, 2 \mathrm{H}), 7.74$ (d, $J=6.31 \mathrm{~Hz}, 2 \mathrm{H}), 7.62-7.46(\mathrm{~m}, 6 \mathrm{H})$. 
Acylhydrazone 1b: 30\%; Mp 150-151 ${ }^{\circ} \mathrm{C} .{ }^{1} \mathrm{H}$ NMR (400 MHz, DMSO-d d $, \mathrm{d}(\mathrm{ppm}): \delta 10.75$ (s, $1 \mathrm{H}), 7.86(\mathrm{~s}, 4 \mathrm{H}), 7.64-7.35(\mathrm{~m}, 6 \mathrm{H}), 2.35(\mathrm{~s}, 3 \mathrm{H})$. MS (70 eV): m/z=238 (7), 223 (23), 105 (100).

Acylhydrazone 1c: $67 \%$; Mp 113-114 ${ }^{\circ} \mathrm{C} .{ }^{1} \mathrm{H}$ NMR $\left(400 \mathrm{MHz}, \mathrm{CDCl}_{3}\right) \delta 7.48-7.46(\mathrm{~m}, 3 \mathrm{H})$, $7.42-7.36(\mathrm{~m}, 4 \mathrm{H}), 7.34-7.26(\mathrm{~m}, 9 \mathrm{H})$. MS (70 $\mathrm{eV}): \mathrm{m} / \mathrm{z}=300$ (30), 223 (9), 195 (7), 165 (10), 105 (100).

\section{SYNTHESIS OF PALLADACYCLES 2a-c}

To a solution of $\mathrm{Li}_{2} \mathrm{PdCl}_{4}(0.99 \mathrm{mmol})$ in methanol $(2 \mathrm{~mL})$ was added a methanolic solution $(3 \mathrm{~mL})$ of the appropriated acylhydrazone 1a-c $(0.99 \mathrm{mmol})$ and sodium acetate $(0.081 \mathrm{~g}, 0.99 \mathrm{mmol})$. The solution was stirred for 3 days at room temperature. After this time, water $(10 \mathrm{~mL})$ was added and the corresponding cyclopalladated complexes precipitated were filtered off. The compounds 2 a-c were obtained with yields between $73-79 \%$.

Compound 2a: 78\%; Mp 180-182 ${ }^{\circ} \mathrm{C} .{ }^{1} \mathrm{H}$ NMR (400 MHz, DMSO-d6) $\delta 7.97$ (d, $J=7.2 \mathrm{~Hz}, 6 \mathrm{H})$, 7.63-7.58 (m, 5H), $7.54-7.50(\mathrm{~m}, 7 \mathrm{H}), 7.08(\mathrm{sl}$, $5 \mathrm{H})$.

Compound 2b: 73\%; Mp 215-216 ${ }^{\circ} \mathrm{C} .{ }^{1} \mathrm{H}$ NMR (400 MHz, DMSO-d6) $\delta 11.84(\mathrm{~s}, 1 \mathrm{H}), 8.53$ -8.24 (m, 22H), 8.20-8.00 (m, 3H), 7.83 (dd, $J=$ $72.3,7.0 \mathrm{~Hz}, 37 \mathrm{H}), 7.68-7.46(\mathrm{~m}, 9 \mathrm{H}), 7.22-6.95$ $(\mathrm{m}, 3 \mathrm{H}), 3.33(\mathrm{~s}, 6 \mathrm{H})$.

Compound 2c: 79\%; Mp 206-209 ${ }^{\circ} \mathrm{C}$. ${ }^{1} \mathrm{H}$ NMR (400 MHz, DMSO-d6) $\delta 11.25$ (sl, 2H), 7.85 (dd, $J=14.4,6.8 \mathrm{~Hz}, 1 \mathrm{H}), 7.74(\mathrm{~d}, J=6.7 \mathrm{~Hz}, 6 \mathrm{H})$, $7.60-7.34$ (m, 16H), 7.05 (d, $J=28.9 \mathrm{~Hz}, 3 \mathrm{H})$, $6.78(\mathrm{~s}, 2 \mathrm{H})$.

\section{REDUCTION OF COMPLEXES 2a-c WITH SODIUM} CYANOBORODEUTERIDE

To a mixture of the appropriated complex 2a-c $(0.125 \mathrm{mmol})$ in THF $(2.5 \mathrm{~mL})$ and $\mathrm{MeOH}$ $(1.25 \mathrm{~mL})$, was added portionwise sodium cyanoborodeuteride $(0.016 \mathrm{~g}, 0.250 \mathrm{mmol})$ at $0{ }^{\circ} \mathrm{C}$ and the mixture was stirred for 1 hour and allowed to reach room temperature. The black precipitate was filtered off, the solvents were evaporated and the residue hydrolyzed with water, extracted with ethyl acetate, the organic layer dried with $\mathrm{Na}_{2} \mathrm{SO}_{4}$, and evaporated. The deuterated acylhydrazones (3a, $\mathbf{3 b}$ and $\mathbf{3 c}$ ) were obtained in 78, 73 and 63\% yields, respectively.

Deuterated acylhydrazone of benzaldehyde 3a: 78\%; Mp 138-140 ${ }^{\circ} \mathrm{C}$. ${ }^{1} \mathrm{H}$ NMR (400 MHz, DMSO-d6) $\delta 11.85$ (s, 1H), 8.48 (s, 1H), 7.93 (d, J $=7.4 \mathrm{~Hz}, 2 \mathrm{H}), 7.74(\mathrm{~d}, J=6.3 \mathrm{~Hz}, 2 \mathrm{H}), 7.54$ (ddd, $J=30.9,19.0,7.0 \mathrm{~Hz}, 7 \mathrm{H}) . \mathrm{MS}(70 \mathrm{eV}): \mathrm{m} / \mathrm{z}=225$ (2\%), 224 (4\%), 121 (20\%), 105 (100), 77 (26).

Deuterated acylhydrazone of acetophenone 3b: 73\%; Mp 200-201 ${ }^{\circ} \mathrm{C}$. ${ }^{1} \mathrm{H}$ NMR (400 MHz, DMSO-d6) $\delta 10.77(\mathrm{~s}, 1 \mathrm{H}), 7.88(\mathrm{sl}, 2 \mathrm{H}), 7.62$ $7.55(\mathrm{~m}, 1 \mathrm{H}), 7.52$ (t, $J=7.3 \mathrm{~Hz}, 2 \mathrm{H}), 7.43(\mathrm{~s}, 3 \mathrm{H})$, 2.37 (s, 3H). MS (70 eV): m/z= 239 (4), 224 (19), 105 (100), 77 (46).

Deuterated acylhydrazone of benzophenone 3c: 63\%; Mp 100-102 ${ }^{\circ} \mathrm{C} .{ }^{1} \mathrm{H}$ NMR (500 MHz, $\left.\mathrm{CDCl}_{3}\right) \delta 9.07(\mathrm{~s}, 1 \mathrm{H}), 7.71(\mathrm{~d}, J=5.2 \mathrm{~Hz}, 1 \mathrm{H})$, $7.62-7.56(\mathrm{~m}, 5 \mathrm{H}), 7.48(\mathrm{dd}, J=12.7,7.4 \mathrm{~Hz}$, $2 \mathrm{H}), 7.39-7.33(\mathrm{~m}, 6 \mathrm{H}) . \mathrm{MS}(70 \mathrm{eV}): \mathrm{m} / \mathrm{z}=301$ (10), 300 (10), 223 (5), 165 (6), 105 (100), 77 (42).

\section{CONCLUSIONS}

In summary, we describe the synthesis of new acylhydrazone-based palladacycles and their application as efficient pre-catalysts in MirozokiHeck and oxyarylation reactions in reasonable to good yield using low catalytic load.

\section{ACKNOWLEDGMENTS}

The authors thank Conselho Nacional de Desenvolvimento Científico e Tecnológico (CNPq), Coordenação de Aperfeiçoamento de Pessoal de Ensino Superior (CAPES), Fundação Carlos Chagas Filho de Amparo à Pesquisa do Estado do Rio de Janeiro (FAPERJ) and Financiadora de 
Estudos e Projetos (FINEP) for financial support and fellowships.

\section{REFERENCES}

ALONSO DA, NÁJERA C AND PACHECO MC. 2000. Oxime Palladacycles: Stable and Efficient Catalysts for Carbon-Carbon Coupling Reactions. Org Lett 13: 18231826.

ALONSO DA, NÁJERA C AND PACHECO MC. 2002. Oxime-Derived Palladium Complexes as Very Efficient Catalysts for the Heck-Mizoroki Reaction. Adv Synth Catal 344: 172-183.

BELETSKAYA IP AND CHEPRAKOV AV. 2004. Palladacycles in Catalysis-A Critical Survey. J Organomet Chem 689: 4055-4082.

BUARQUE CD, PINHO VD, VAZ BG, EBERLIN MN, DA SILVA AJM AND COSTA PRR. 2010. PalladiumCatalyzed Oxyarylation of Olefins Using Silver Carbonate as the Base. Probing the Mechanism by Electrospray Ionization Mass Spectrometry. J Organomet Chem 695: 2062-2067.

CARDENAS DJ AND ECHAVARREN AM. 1995. Selectivity in the Aliphatic Palladation of Ketone Hydrazones. An Example of Palladium-Promoted Intramolecular Addition of a N,N-Dimethylhydrazone to an Alkene. Organometallics 14: 4427-4430.

DE MORAES PF, GASPAR FV, BORGES RHF, NETTO CD, LEÃO RAC, NÁJERA C AND COSTA PRR. 2015. Ligand Free Palladium-Catalyzed Oxyarylation of Dihydronaphthalens and Chromenequinone with $o$-Iodophenols and 3-Iodolawsone in PEG-400: An Efficient Synthesis of 5-Carba-Pterocarpans and Pterocarpanquinones. Synthesis 47: 3505-3512.

DUPONT J, CONSORTI CS AND SPENCER J. 2005. The Potential of Palladacycles: More Than Just Precatalysts. Chem Rev 105: 2527-2571.
FRAGA CAM AND BARREIRO EJ. 2006. Medicinal Chemistry of N-Acylhydrazones: New Lead-Compounds of Analgesic, Antiinflammatory and Antithrombotic Drugs. Curr Med Chem 13: 167-198.

HERRMANN WA, BÖHM VPW AND REISINGER C-P. 1999. Application of Palladacycles in Heck Type Reactions. J Organomet Chem 576: 23-41.

HERRMANN WA, BROSSMER C, KFELE K, REISINGER C-P, PRIERMEIER T, BELLER M AND FISCHER H. 1995. Palladacycles as Structurally Defined Catalysts for the Heck Olefination of Chloro- and Bromoarenes. Angew Chem Int Edit 34: 1844-1848.

KISS L, KURTAN T, ANTUS S AND BRUNNER H. 2003. Further Insight into the Mechanism of Heck Oxyarylation in the Presence of Chiral Ligands. Arkivoc 2003(5): 69-76.

LAROCK RC. 1998. Synthesis of Substituted Pterocarpans, U.S. Patent 5721371.

LEÃO RAC, PINHO VD, COELHO AS, BUARQUE CD, MORAES PF, ALONSO DA, NÁJERA C AND COSTA PRR. 2011. Microwave-Promoted Palladium-Catalysed Oxyarylation of Dihydronaphthalene and Chromenes by $o$-Iodophenols and its Acetates. Eur J Org Chem 33133316.

NAGY TZ, CSÁMPAI A AND KOTSCHY A. 2005. Ferrocenyl-Palladium Complexes in Cross-Coupling Reactions: A Comparative Study. Tetrahedron 61: $9767-$ 9774.

NÁJERA C. 2016. Oxime-Derived Palladacycles: Applications in Catalysis. ChemCatChem 8: 1865-1881.

SHAW BL. 1998. Speculations on New Mechanisms for Heck Reactions. New J Chem 22: 77-79.

SHAW BL, PERERA SD AND STALEY EA. 1998. Highly Active, Stable, Catalysts for the Heck Reaction; Further Suggestions on the Mechanism. Chem Commun 13611362 . 